\title{
BMJ Open Cross-sectional association between long working hours and endoscopic gastritis: the Kangbuk Samsung Health Study
}

\author{
Eunchan Mun (D) , ${ }^{1}$ Yesung Lee (D) , ${ }^{1}$ Woncheol Lee (D) , Soyoung Park (D) ${ }^{1,2}$
}

To cite: Mun E, Lee $\mathrm{Y}$, Lee W, et al. Cross-sectional association between long working hours and endoscopic gastritis: the Kangbuk Samsung Health Study. BMJ Open 2021;11:e050037. doi:10.1136/ bmjopen-2021-050037

- Prepublication history for this paper is available online. To view these files, please visit the journal online (http://dx.doi. org/10.1136/bmjopen-2021050037).

Received 09 February 2021 Accepted 17 August 2021

\section{Check for updates}

(c) Author(s) (or their employer(s)) 2021. Re-use permitted under CC BY-NC. No commercial re-use. See rights and permissions. Published by BMJ.

${ }^{1}$ Department of Occupational and Environmental Medicine, Kangbuk Samsung Hospital, Sungkyunkwan University School of Medicine, Seoul, Republic of Korea

${ }^{2}$ Total Healthcare Center, Kangbuk Samsung Hospital, Sungkyunkwan University School of Medicine, Seoul, Republic of Korea

Correspondence to Dr Soyoung Park; syoem.park@gmail.com

\begin{abstract}
Objectives This study aimed to determine the crosssectional association between long working hours and gastritis diagnosed by endoscopy.

Design Cross-sectional study.

Setting Large university hospitals in Seoul and Suwon, South Korea.

Participants Workers in formal employment who underwent a comprehensive health examination at the Kangbuk Samsung Hospital Total Healthcare Centre clinics in Seoul and Suwon, South Korea, between January 2011 and December 2018. Of the 386488 participants, 168391 full-time day workers met the inclusion criteria and were included in the analysis.
\end{abstract}

Primary outcome measure Endoscopic gastritis. Results The participants were predominantly college graduates or above $(88.9 \%)$, male $(71.2 \%)$ and in their 30 s $(51.1 \%)$, and the median age was 36 (IQR $31-42$ ). Approximately $93.2 \%$ of participants had positive endoscopic gastritis, and there was a significant association between working hours and positive findings of endoscopic gastritis. The multivariate fully adjusted prevalence ratio (PR) of endoscopic gastritis for participants working $>55$ hours per week compared with 35-40 hours per week was 1.011 (95\% Cl 1.007 to 1.015). Furthermore, endoscopic findings were classified into nine subtypes of gastritis, including superficial gastritis, erosive gastritis, atrophic gastritis, intestinal metaplasia and haemorrhagic gastritis increased with longer working hours ( $p$ for trends $<0.05$ ). Their PRs for participants working $>55$ hours per week compared with $35-40$ hours per week were 1.019 (95\% Cl 1.012 to 1.026), 1.025 (95\% Cl 1.011 to 1.040$), 1.017$ (95\% Cl 1.008 to 1.027$)$, $1.066(95 \% \mathrm{Cl} 1.028$ to 1.105$)$ and $1.177(95 \% \mathrm{Cl} 1.007$ to $1.375)$, respectively.

Conclusions Working over 55 hours per week was crosssectionally associated with positive findings of endoscopic gastritis. The study findings indicated potentially increased risks of superficial gastritis, erosive gastritis, atrophic gastritis, intestinal metaplasia and haemorrhagic gastritis among workers with long working hours ( $>55$ hours per week), supporting the need for further exploration via longitudinal studies.

\section{BACKGROUND}

Working long hours is a significant occupational health issue that reduces work efficiency and threatens workers' health. Global

\section{Strengths and limitations of this study}

- This study investigated a large sample size of 168391 participants' endoscopic findings for crosssectional analyses.

- The outcome measure for gastritis was defined by objective endoscopic findings to overcome methodological limitations of using subjective self-reported symptoms.

- We focused on long working hours and minimised work-schedule-biased health effects by excluding shift and part-time workers from the study participants, and adjusted the analysis using multiple demographic and clinical screening factors from clinical records.

- The generalisability of the study findings should be verified, as the study included only relatively young and well-educated Korean men and women in formal full-time employment.

- The cross-sectional nature of the study design makes it difficult to determine causal inference.

trends are moving towards reducing work hours. ${ }^{1}$ Many countries have reduced their statutory working hours from 48 to 40 hours per week. ${ }^{2}$ South Korea was among them, revising the Labor Standards Act in 2018 to limit the legal working limit to 40 hours per week, with 52 hours as the maximum limit even with overtime. However, these laws are not applied to workplaces with less than 50 employees, and there are exceptions in some transport and health industries. ${ }^{3}$ Until 2019 , South Korea had the third-longest work week among Organisation for Economic Co-operation and Development countries. ${ }^{4}$

Many studies have found that workers with long working hours are at risk of various clinical diseases, such as coronary heart disease, ${ }^{5}$ atrial fibrillation, ${ }^{6}$ hypertension, ${ }^{7}$ stroke, ${ }^{5} 8$ metabolic syndrome, ${ }^{9}$ diabetes mellitus, ${ }^{10}$ non-alcoholic fatty liver disease, ${ }^{11}$ depression, sleep disorder and all-causes mortality. ${ }^{12}$ Although the causal pathways have not been fully explored, an irregular and unhealthy lifestyle, including smoking 
and alcohol use, ${ }^{13} 14$ and psychosocial stress caused by long working hours ${ }^{915}$ have been considered the main contributing factors. Furthermore, these factors can cause more frequent abdominal symptoms and gastrointestinal disease,${ }^{1617}$ and thus long working hours might cause gastrointestinal problems.

Globally, gastritis is a common, life-long, serious and insidious illness and is relatively well-researched. Even though the prevalence of gastritis has declined in developed populations, gastritis is still one of the most common pandemic disease that affects more than half of global population. ${ }^{18}$ In South Korea, the guidelines of the National Cancer Screening Programme recommended undergoing a biennial upper gastrointestinal series or oesophagogastroduodenoscopy (OGD) for those over 40 years of age, regardless of symptoms. ${ }^{19}$ Additionally, a lot of companies are offering welfare to employees by providing additional endoscopy regardless of symptoms during the free annual or biennial health screenings guaranteed by South Korean Industrial Safety and Health Law. According to a nationwide study of these endoscopic screenings, the prevalence of gastritis diagnosed by endoscopy in South Korea was estimated to $85.9 \% .{ }^{20}$ Although various factors such as high Helicobacter pylori infection rate and unhealthy lifestyle behaviours might contribute to this high prevalence, there are few studies about whether occupational demands influence gastritis.

Some studies have suggested that long working hours cause gastrointestinal complaints; ${ }^{21}{ }^{22}$ however, to the best of our knowledge, there has been no study on the association between long working hours and objective endoscopic findings for gastritis. Therefore, this study aimed to investigate the association between long working hours and gastritis diagnosed by endoscopy.

\section{METHODS}

\section{Study design and participants}

This is a cross-sectional study of participants in the Kangbuk Samsung Health Study, which was conducted between January 2011 and December 2018 (n=386 488). The Kangbuk Samsung Health Study is a cohort of Korean men and women aged 18 years or older who underwent comprehensive health screening at the clinics of the Kangbuk Samsung Hospital Total Healthcare Centre in Seoul and Suwon, South Korea. The screening programme included anthropometric measurements, annual or biennial endoscopy and abdominal sonography, various laboratory studies and an epidemiological questionnaire on lifestyle factors, medication and chronic disease. More than $80 \%$ of participants were employees of various companies and local governmental organisations, or their spouses, because the South Korean Industrial Safety and Health Law provides free annual or biennial health screenings for employees. The remaining participants voluntarily paid for these screening examinations. In the case of multiple visits, the first visit was investigated rather than the last, to prevent further increase of causal interference in the cross-sectional study. The exclusion criteria were shift workers working between 18:00 and 06:00; working < 35 hours per week; not having undergone an endoscopy or experience of endoscopy failure; a history of cancer derived from the database of the National Cancer Registration and Statistics Programme; being prescribed non-steroidal anti-inflammatory drugs or aspirin for more than a week within the last month; being prescribed steroids for more than 3 months; and missing covariate data. In total, 168391 full-time day workers were included in the analysis (figure 1).

\section{Measurement of variables}

Data on age, sex, smoking status, alcohol intake, exercise habits, marital status, education level, abdominal symptoms, medication and weekly working hours on average in the last year were obtained using a self-administered questionnaire and reviewed during a face-to-face doctor's interview. Working hours were identified using the following question: 'How many hours did you work in a week on average in your job for the past year, including overtime?'. Regarding alcohol intake, alcohol consumption (grams per day) was calculated using the frequency and amount of beverages consumed per day and categorised into excessive alcohol consumption ( $\geq 30 \mathrm{~g} /$ day for men and $\geq 20 \mathrm{~g} /$ day for women) and moderate alcohol consumption $(<30 \mathrm{~g} /$ day for men and $<20 \mathrm{~g} /$ day for women). ${ }^{23}$ Exercise habits were evaluated using the questionnaire: 'frequency of vigorous leisure-time physical activity per week', and categorised into 'yes' (more than once per week) or 'no'. Abdominal symptoms were defined by having more than one of the following symptoms: water brash, nausea, feeling not easy to digest, burning sensation and frequent abdominal pain.

Trained nurses measured clinical factors such as height, body weight and waist circumference, and blood parameters were measured using venous blood samples collected from the antecubital vein after $\geq 10$ hours of fasting. Body mass index (BMI) was calculated by dividing the measured weight $(\mathrm{kg})$ by the square of the height $\left(\mathrm{m}^{2}\right)$; based on the calculated BMI, patients were classified as being obese $\left(\geq 25 \mathrm{~kg} / \mathrm{m}^{2}\right)$, which is the proposed cutoff for the diagnosis of obesity in Asians, or not obese $\left(<25 \mathrm{~kg} / \mathrm{m}^{2}\right) .{ }^{24}$ An enzymatic colorimetric assay measured the total serum cholesterol, high-density lipoprotein cholesterol (HDL-C), low-density lipoprotein cholesterol (LDL-C) and triglyceride levels. Based on cut-off values related to the potential risk of developing coronary heart disease ${ }^{25}$ total cholesterol was categorised into $\geq 200 \mathrm{mg}$ / $\mathrm{dL}$ and $<200 \mathrm{mg} / \mathrm{dL}, \mathrm{HDL}-\mathrm{C}$ was categorised into $<40 \mathrm{mg} /$ $\mathrm{dL}$ for men and $<50 \mathrm{mg} / \mathrm{dL}$ for women, or $\geq 40 \mathrm{mg} / \mathrm{dL}$ for men and $\geq 50 \mathrm{mg} / \mathrm{dL}$ for women and triglyceride level was categorised into $\geq 150 \mathrm{mg} / \mathrm{dL}$ and $<150 \mathrm{mg} / \mathrm{dL}$. Serum fasting glucose levels were measured using the hexokinase method on a Cobas Integra 800 apparatus (Roche Diagnostics, Tokyo, Japan). Haemoglobin A1c (HbA1c) level was measured using an immunoturbidimetric assay with a Cobas Integra 800 automatic analyser. Glucose 
386,488 individuals who underwent

comprehensive health examinations between January

2011 and December $2018(N=386,488)$

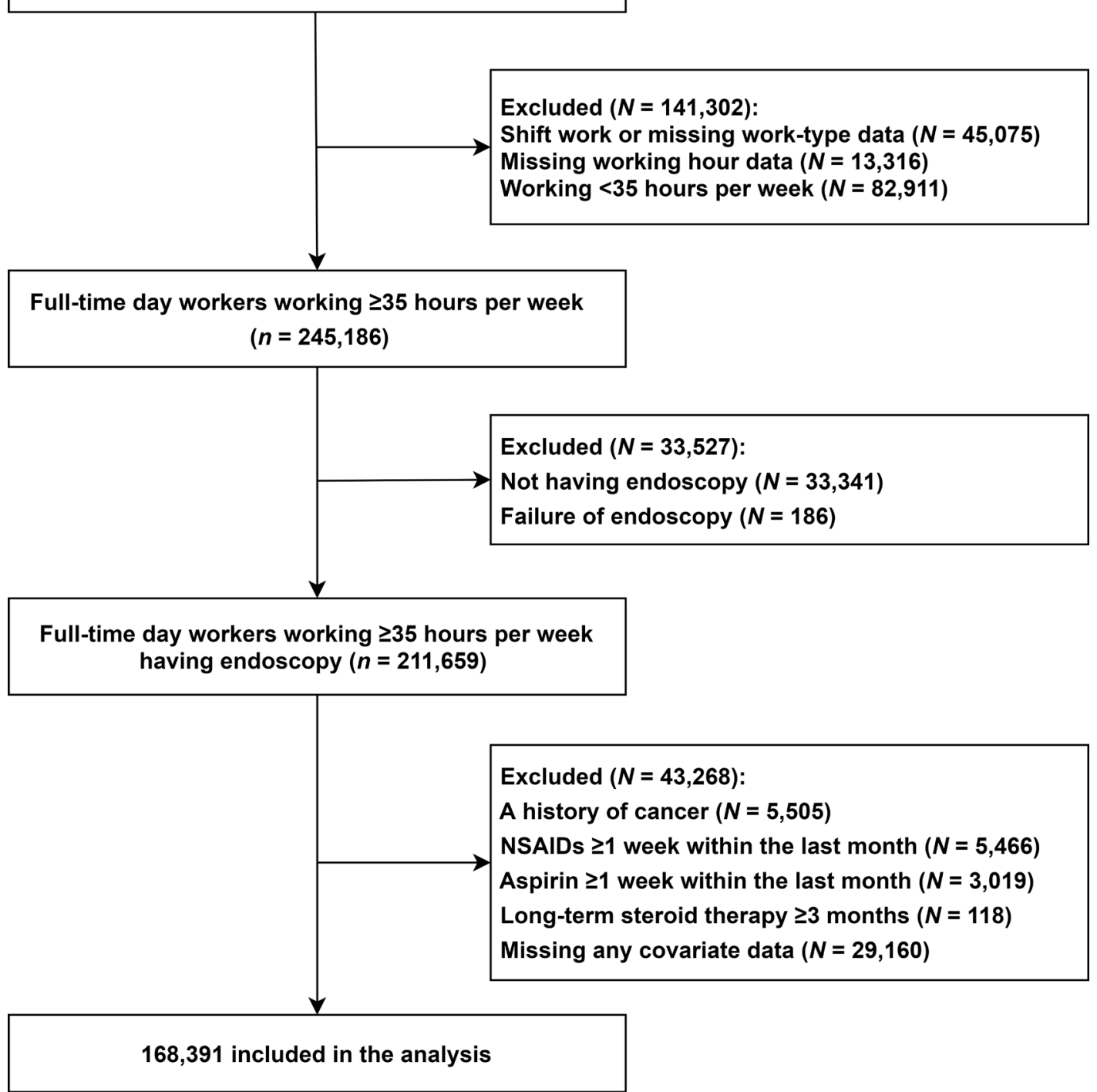

Figure 1 Participant selection flowchart. NSAIDs, non-steroidal anti-inflammatory drugs.

level was categorised into $\geq 126 \mathrm{mg} / \mathrm{dL}$ and $<126 \mathrm{mg} / \mathrm{dL}$ and $\mathrm{HbA1c}$ level was categorised into $\geq 6.5 \%$ and $<6.5 \%$ according to the diagnostic criteria of diabetes. ${ }^{26}$ All laboratory tests were conducted at the Laboratory Medicine Department of Kangbuk Samsung Hospital in Seoul, South Korea, which is accredited by the Korean Society of Laboratory Medicine and the Korean Association of Quality Assurance for Clinical Laboratories.

Standardised endoscopic examinations were conducted by 1 of 26 experienced board-certified endoscopiologists using conventional white light endoscopes with singlechannel (GIF-H260; Olympus Optical, Tokyo, Japan). The endoscopic findings and diagnosis were described and determined by the endoscopiologist who performed endoscopy. 1 of 26 experienced board-certified endoscopiologists using conventional white light endoscopes with single-channel (GIF-H260). The endoscopic findings and diagnosis were described and determined by the endoscopiologist who performed endoscopy.

\section{Classification of working hours}

Full-time workers were those who work $\geq 35$ hours per week, and working 35-40 hours per week was defined as standard working hours. ${ }^{2}$ The Hours of (Industry) Convention provided a maximum standard working time of 48 hours per week as an international norm. ${ }^{27}$ Additionally, a lot of occupational epidemiological studies have shown the adverse health effects of exposure to working more than 55 hours per week. However, in 2016, it was estimated that working more than 55 hours per week is still common among 488 million people globally. ${ }^{5}$ Accordingly, working hours in this study were classified into $35-40,41-48,49-55$ and $>55$ hours per week, with long working hours defined as $>55$ hours weekly. 


\section{Classification of endoscopic gastritis}

Endoscopic findings of gastritis were based on the Sydney classification. ${ }^{28}$ In our study, erythematous or exudate was classified as superficial gastritis, and flat erosive or raised erosive as erosive gastritis, following the practical terminology used in Korean academic practice. ${ }^{20}$ Atrophic gastritis, haemorrhagic gastritis, reflux gastritis and hyperplastic gastritis were classified according to the Sydney classification system. Additionally, intestinal metaplasia, gastric ulcer and nodular gastritis were further classified. As a result, the following nine categories were established: superficial gastritis, erosive gastritis, atrophic gastritis, haemorrhagic gastritis, reflux gastritis, hyperplastic gastritis, intestinal metaplasia, gastric ulcer and nodular gastritis. Multiple endoscopic findings were recorded in a single examination as applicable, and all endoscopic findings were classified in the medical records by the endoscopy specialist who performed the endoscopy.

\section{Statistical analysis}

For the descriptions of general characteristics of study participants and the distribution of subtypes of gastritis, categorical variables were expressed as a percentage $(\%)$ and analysed using the $\chi^{2}$ test. Non-normally distributed continuous variables were expressed as median values with IQRs and were analysed using the Mann-Whitney U test. A normality test was performed using the KolmogorovSmirnov test. The Poisson regression model with robust variance was used to determine the association between working hours and endoscopic gastritis, and the results were expressed as prevalence ratios (PRs) with 95\% CIs rather than ORs, considering the high prevalence of gastritis. We performed a bivariate Poisson regression analysis, followed by age and sex adjustment, and further multivariate adjustment for lifestyle factors of smoking status, alcohol intake and exercise for Model 1. Additionally, social status factors of marital status and education level were further adjusted for Model 2, followed by further adjustment of metabolic factors of glucose, HbA1c, BMI, waist circumference, total cholesterol, HDL-C, LDL-C and triglycerides for Model 3. In the fully adjusted Model 4, abdominal symptoms and digestive medication were further adjusted. In the adjustments, continuous covariates were categorised as defined in the Measurement of variable section. Two-sided $p$ values $<0.05$ were considered statistically significant, unless otherwise indicated. For multiple comparisons, Bonferroni adjustment was used to reduce the probability of type 1 error. All statistical analyses were performed using SPSS software (V.24.0; IBM).

\section{Patient and public involvement}

Patients and/or the public were not involved in the design, conduct, reporting or dissemination plans of this research.

\section{RESULTS}

\section{Participant characteristics}

The median age was 36 (IQR, 31-42) years, and the majority $(71.2 \%)$ of the participants were men. The majority were married $(75.0 \%)$ and had a college degree or higher $(88.9 \%)$. In total, $93.2 \%$ of the participants had one or more endoscopic findings of gastritis, and there were significant differences in age, sex, smoking status, alcohol intake, exercise, marital status, glucose, HbAlc, BMI, waist circumference, total cholesterol, HDL-C, LDL-C, triglycerides, digestive medication and working hours per week between the normal group and the endoscopic gastritis group (table 1).

\section{Distribution of endoscopic gastritis in the study participants}

Of the 168391 study participants, 168213 (99.9\%) had classifiable endoscopic results, including 11435 (6.8\%) with normal findings; the remaining $178(0.1 \%)$ endoscopic findings of gastritis were not sub-classified. Overall, 156956 (93.2\%) participants had more than one endoscopic finding of gastritis in a single endoscopy, as shown in table 1 . The distribution of sex and age is described in table 2. The most common finding of gastritis was superficial gastritis $(53.9 \%)$, followed by atrophic gastritis $(25.7 \%)$, erosive gastritis $(18.9 \%)$, intestinal metaplasia $(3.4 \%)$, gastric ulcer $(0.8 \%)$, haemorrhagic gastritis $(0.8 \%)$, nodular gastritis $(0.7 \%)$, reflux gastritis $(0.1 \%)$, unclassified gastritis $(0.1 \%)$ and hyperplastic gastritis $(0.02 \%)$. Erosive gastritis, atrophic gastritis, intestinal metaplasia, gastric ulcer and hyperplastic gastritis were more common in men and tended to increase with age, while superficial gastritis, nodular gastritis and reflux gastritis were more common in young women, and haemorrhagic gastritis was more common in young men. All the $\mathrm{p}$ values and $\mathrm{p}$ for trends were $<0.05$ (table 2 ).

\section{Association between working hours and endoscopic gastritis}

In the multivariate fully adjusted logistic regression model (Model 4), there were positive associations between working hours and endoscopic gastritis findings. Working $>55$ hours per week compared with 35-40 hours was significantly associated with endoscopic gastritis, and the PR was 1.011 (95\% CI 1.007 to 1.015 ). All p values for trends were $<0.001$ (table 3 ).

\section{Association between working hours and endoscopic gastritis subtypes}

The associations between working hours and subtypes of gastritis were analysed by multivariate fully adjusted regression. Superficial gastritis, erosive gastritis, atrophic gastritis, intestinal metaplasia and haemorrhagic gastritis were found to be significantly associated with working $>55$ hours per week; the PRs for $>55$ hours per week compared with 35-40 hours per week were 1.019 (95\% CI 1.012 to 1.026 ), 1.025 (95\% CI 1.011 to 1.040 ), 1.017 (95\% CI 1.008 to 1.027 ), 1.066 (95\% CI 1.028 to 1.105 ) and 1.177 (95\% CI 1.007 to 1.375 ), respectively, and all their $\mathrm{p}$ values for trends were $<0.05$ (table 4 ). 
Table 1 General characteristics of the study participants

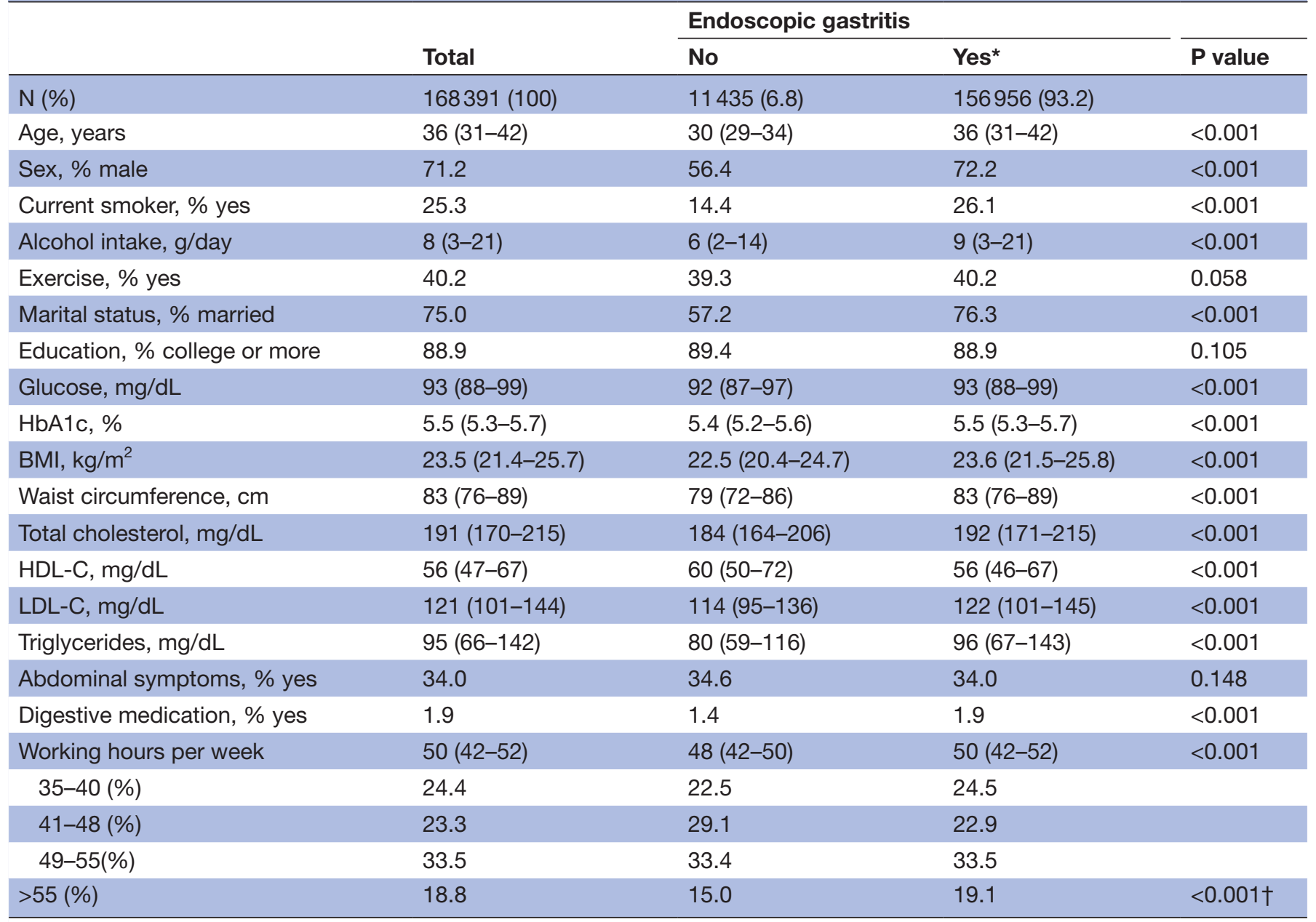

Data are presented as number (\%), median (IQR) or percentages.

${ }^{*}$ Participants who had more than one endoscopic finding of gastritis.

†Significance level is set as $<0.01(0.05 / 4)$ based on Bonferroni adjustment for multiple comparisons.

$\mathrm{BMl}$, body mass index; HbA1c, haemoglobin A1c; HDL-C, high-density lipoprotein cholesterol; LDL-C, low-density lipoprotein cholesterol.

\section{DISCUSSION}

\section{Principal findings}

In this study, we found that working over 55 hours per week was cross-sectionally associated with endoscopic gastritis. In particular, among gastritis subtypes, superficial gastritis, erosive gastritis, atrophic gastritis, intestinal metaplasia and haemorrhagic gastritis were significantly associated with long working hours ( $>55$ hours per week).

\section{Prevalence of endoscopic gastritis}

It is estimated that more than half the global population has gastritis. ${ }^{18}$ South Korea is a country with an extremely high prevalence of gastritis, and $93.2 \%$ of the participants had endoscopic gastritis. Similarly, Sung et al and Park et al reported a high prevalence of gastritis in South Korean adults, at $81.7 \%$ and $85.9 \%$, respectively. ${ }^{20}{ }^{29}$ Park et al suggested that this high prevalence might be due to factors such as high $H$. pylori infection rate and unhealthy lifestyle behaviours including high salt intake and alcohol consumption in South Korea. ${ }^{20}$ Comparing the results, in our study intestinal metaplasia was significantly less frequent $(3.4 \%$ vs $7.1 \%)$, while superficial gastritis was much more frequent (53.9\% vs $31.3 \%$ ). The differences might be owing to the demographic characteristics of our study group: mostly young and with a high socioeconomic status (SES).

\section{Psychosocial stress and gastritis}

It has been suggested that long working hours act both directly as a work-related stressor that augments job demands needed to maintain performance levels against increasing fatigue, and indirectly by increasing the time for which workers are exposed to other sources of workrelated stressors. ${ }^{22}$ Although the underlying mechanism is not fully explored, several studies have theoretically shown that psychosocial stress can affect the development of both upper and lower gastrointestinal disease, including inflammatory bowel disease, irritable bowel syndrome, and other functional gastrointestinal diseases, food antigen-related adverse responses, peptic ulcer and gastro-oesophageal reflux disease. Currently, the brain-gut axis is one of the most reliable pathways since 

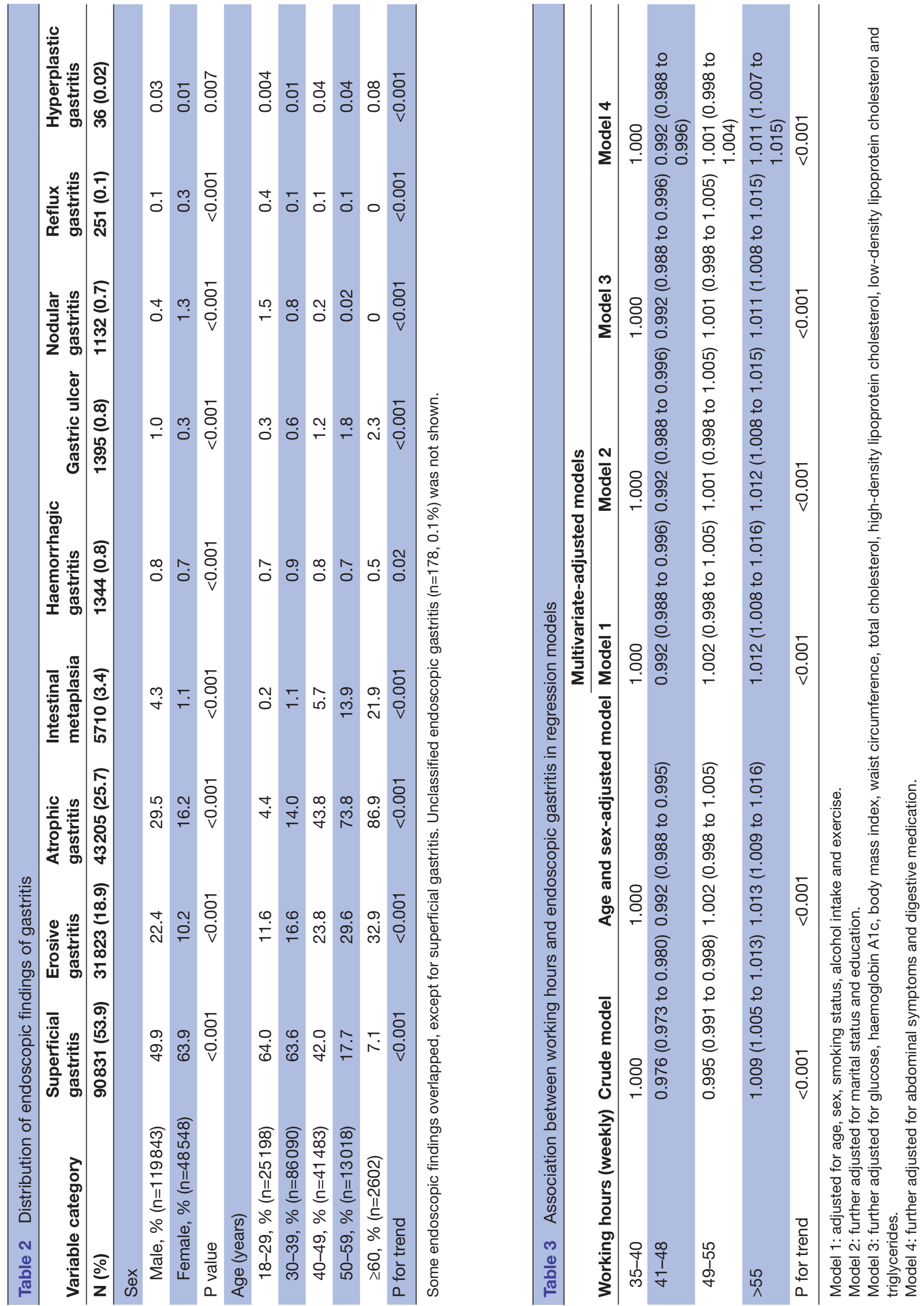


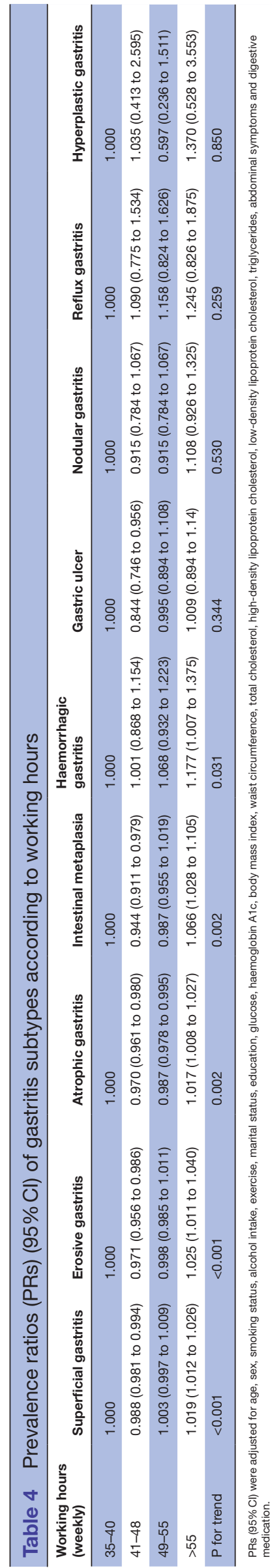

psychosocial stress could alter gastric physiology through alterations in gastric acid secretion, reduced mucosal blood flow, reduced $\mathrm{HCO}_{3}^{-}$secretion, acid back diffusion, reduced proliferation and restitution of the injured mucosa, and alterations in gastric motility. ${ }^{1630-33}$

Several in vivo studies on animal models have supported biological plausibility for the association between psychological stress and gastritis. Guo et al have shown that $H$. pylori colonisation of the gastric mucosa of BALB/c mice is enhanced by psychological stress, and that this effect may be mediated by excess glucocorticoids produced by psychological stress. ${ }^{34}$ Kim et al have shown that long-term psychological stress can induce gastric mucosal inflammation and erosions, even independent of $H$. pylori infection in C57BL/ 6 mice ${ }^{35}$ Fatemeh et al have shown that psychological stress increases gastric acid and pepsin secretions in rats, possibly by raising gastric tissue nitric oxide levels. ${ }^{36}$ Xie $e$ t al have reported that parasympathetic overactivity is possibly the leading cause of psychological stress-induced gastric mucosal lesion in rats. ${ }^{37}$ Han et al have shown that psychological stress in mice can induce gastritis via gastric microbial dysbiosis and hydrogen sulfide reduction. ${ }^{38}$ In clinical aspects, several human subjects studies also support a positive association between psychosocial stress and gastritis. Chadolias et al examined 891 individuals for gastrointestinal disorders and reported that work-related psychosocial stress is strongly associated with an increased risk of developing a gastritis (OR: 2.182, 95\% CI 1.072 to 4.444). ${ }^{39}$ In conducting a hospital-based cross-sectional study of 400 patients, Mahmoud et al showed that psychological stress is an important predictor of gastritis (OR: $2.85,95 \%$ CI 1.81 to 4.48$).{ }^{40}$ Through a cross-sectional analysis of 364 patients, Feyisa and Woldeamanuel reported that psychological stress could contribute to gastritis (OR: 2.168; $95 \%$ CI 1.046 to 2.174 ). ${ }^{41}$

Since long working hours induce work-related psychosocial stress, psychosocial stress could mediate the association between long working hours and gastritis. Considering the proposed mechanisms, further studies should include job stress or stressors in the analysis, to determine whether work-related psychosocial stress mediates the association between long working hours and gastritis.

\section{Potential confounders}

Sex differences could affect the association between long working hours and endoscopic gastritis. Several studies have shown that upper digestive disorders were more common in men, and in our study, men were more likely to have endoscopic gastritis. This tendency could be explained by the higher prevalence of $H$. pylori infection, differences in the mucosal system, ${ }^{42}$ and unhealthy lifestyle habits such as smoking and drinking that are more prevalent in men. ${ }^{20}$ Since unhealthy behaviours are related to long working hours, ${ }^{13}{ }^{14}$ these factors were included in the multivariate-adjusted models along with sex. However, we found consistent results despite further adjustment for lifestyle factors of smoking status, alcohol 
intake and exercise, in addition to age and sex. This means that the mediation effect of lifestyle factors on the association between long working hours and gastritis was not significant.

Metabolic syndrome and its components have been considered risk factors for upper gastrointestinal disease through various pathways, including altered secretion of bioactive substances such as adipocytokines and adiponectin. ${ }^{43}$ A meta-analysis of evidence from 1998 to 2018 indicated that metabolic syndrome was related to long working hours (OR: 1.110, p<0.01). ${ }^{9}$ However, in our study, the effect size did not decrease significantly after further adjustment of metabolic components from Model 2 to Model 3. Therefore, we must exercise caution in interpreting metabolic change as a mediator of the association between long working hours and gastritis in our study findings.

SES and education levels are well-known to be closely related to $H$. pylori infection. ${ }^{44}$ Our study participants were formally employed workers, and well educated: $88.9 \%$ had completed college. Since the Kangbuk Samsung Health Study has relatively homogeneous characteristics, with high SES and education levels, we expected the effect of SES differences to have low significance in our study.

Shift work could be further related to gastrointestinal disorders, and an impaired circadian rhythm has been suggested as the main contributing factor. ${ }^{45}{ }^{46}$ Some work long hours at night or until night-time, and they might be affected by both long working hours and shift work. Bannai and Tamakoshi, who conducted a systematic review of the health risk of long working hours, strongly suggested future researchers take this into account. ${ }^{12}$ In a subsequent systematic review and metaanalysis of the effect of long working hours, only studies investigating daytime workers, like our study, were analysed to prevent the deviated effects caused by different work schedules. ${ }^{9}$

\section{Clinical significance of the results}

Superficial gastritis, erosive gastritis, atrophic gastritis, intestinal metaplasia and haemorrhagic gastritis had a positive relationship with working hours after fully adjusting for potential confounders. Although superficial gastritis generally not require a specific treatment unless symptoms develop, it could be the first step in carcinogenesis of gastric cancer, followed by atrophic gastritis, intestinal metaplasia, dysplasia and adenocarcinoma. ${ }^{47-49}$ Persistent superficial gastritis also predisposes people to duodenal ulcer and gastric mucosa-associated lymphoid tissue lymphoma. ${ }^{50}$ Haemorrhagic gastritis is a condition that involves acute diffuse superficial erosions or multiple petechial haemorrhages of the mucosa. It is a vital cause of upper gastrointestinal bleeding that often needs aggressive medical and endoscopic therapy. ${ }^{51-53}$ Even though the effect size of long working hours themselves was small, our study provides novel evidence of the health risk of long working hours.

\section{Strengths and limitations}

Our study has some limitations. First, its cross-sectional design made it difficult to determine causality. Longitudinal studies are required for confirmation of the causality nature of the relationship. Second, occupational characteristics data such as working hours were collected from a questionnaire, which may have resulted in selfreport bias. Third, the effect of working hours on gastritis might vary with occupational factors such as work type, work intensity and work environment, which were not adequately considered here. Further research needs to consider more specific and concrete occupational factors to analyse the effects of long working hours. Fourth, our study was conducted in relatively young and well-educated Korean men and women who were in formal full-time employment. Therefore, despite the large sample size, the generalisability of our findings to other populations needs to be verified. The effect of long working hours could be underestimated in our study since higher SES could act as a protective factor in disease occurrence.

Nonetheless, we believe that our study remains valuable because, to the best of our knowledge, this is the first large-scale study to evaluate the association between long working hours and gastritis by using objective endoscopic findings, as opposed to relying on self-reported symptoms. Additionally, our study effectively focused on long working hours, since we excluded shift and parttime workers from the study participants to minimise work-schedule-biased health effects, and we adjusted the analyses for multiple demographic and clinical screening factors drawn from clinical records.

\section{CONCLUSIONS}

This cross-sectional study verified the association between working over 55 hours per week and gastritis, using OGD results from a considerable amount of health examination data. The study findings indicated potentially increased risks of superficial gastritis, erosive gastritis, atrophic gastritis, intestinal metaplasia and haemorrhagic gastritis among workers with long working hours ( $>55$ hours per week). Further longitudinal studies are required to confirm the risk of gastritis due to long working hours.

Contributors EM, YL and SP contributed to the conception and design of the study. EM, YL and WL participated in the data collection and made substantial contributions to the statistical analysis and interpretation of the data. EM and SP prepared the first draft of the manuscript. WL and SP made substantial contributions to revising the manuscript critically for important intellectual content. All authors have approved the final version submitted for publication.

Funding The authors have not declared a specific grant for this research from any funding agency in the public, commercial or not-for-profit sectors.

Competing interests None declared.

Patient and public involvement Patients and/or the public were not involved in the design, or conduct, or reporting, or dissemination plans of this research.

Patient consent for publication Not required.

Ethics approval The study was approved by the institutional review board of Kangbuk Samsung Hospital (approval number: KBSMC 2020-05-040). The requirement for informed consent was waived owing to the use of deidentified data. 
Provenance and peer review Not commissioned; externally peer reviewed.

Data availability statement Data are available upon reasonable request. The datasets used and/or analysed during the current study are available from the corresponding author on reasonable request.

Open access This is an open access article distributed in accordance with the Creative Commons Attribution Non Commercial (CC BY-NC 4.0) license, which permits others to distribute, remix, adapt, build upon this work non-commercially, and license their derivative works on different terms, provided the original work is properly cited, appropriate credit is given, any changes made indicated, and the use is non-commercial. See: http://creativecommons.org/licenses/by-nc/4.0/.

\section{ORCID iDs}

Eunchan Mun http://orcid.org/0000-0002-2808-0423

Yesung Lee http://orcid.org/0000-0002-8844-492X

Woncheol Lee http://orcid.org/0000-0001-8535-3988

Soyoung Park http://orcid.org/0000-0003-2163-5892

\section{REFERENCES}

1 Messenger JC, Lee S, McCann D. Working time around the world: trends in working hours, laws, and policies in a global comparative perspective. London: Routledge, 2007.

2 International Labour Organization. Working time in the twenty-first century: discussion report for the tripartite meeting of experts on working-time arrangements 2011. International Labour Office. Geneva: ILO, 2011. https://www.ilo.org/travail/whatwedo/ publications/WCMS_161734/lang--en/index.htm

3 Ministry of Employment and Labor (KR). Chapter IV: working hours and recess. In: Labor standard act. Sejong: Ministry of Employment and Labor, 2012. http://www.moel.go.kr/english/download eng.jsp? type=\&file=(31)LABORSTANDARDSACT_2012.pdf

4 OECDiLibrary. Hours worked. Available: https://www.oecd-ilibrary. org/employment/hours-worked/indicator/english_47be1c78-en [Accessed 12 Oct 2020]

5 Pega F, Náfrádi B, Momen NC, et al. Global, regional, and national burdens of ischemic heart disease and stroke attributable to exposure to long working hours for 194 countries, 2000-2016: a systematic analysis from the WHO/ILO joint estimates of the workrelated burden of disease and injury. Environ Int 2021;154:106595.

6 Kivimäki M, Nyberg ST, Batty GD, et al. Long working hours as a risk factor for atrial fibrillation: a multi-cohort study. Eur Heart $J$ 2017;38:2621-8

7 Trudel X, Brisson C, Gilbert-Ouimet M, et al. Long working hours and the prevalence of masked and sustained hypertension. Hypertension 2020;75:532-8

8 Fadel M, Sembajwe G, Gagliardi D, et al. Association between reported long working hours and history of stroke in the CONSTANCES cohort. Stroke 2019;50:1879-82.

9 Wong K, Chan AHS, Ngan SC. The effect of long working hours and overtime on occupational health: a meta-analysis of evidence from 1998 to 2018. Int J Environ Res Public Health 2019;16:2102.

10 Bannai A, Yoshioka E, Saijo Y, et al. The risk of developing diabetes in association with long working hours differs by shift work schedules. J Epidemiol 2016;26:481-7.

11 Park H, Lee S-J. Working hours and nonalcoholic fatty liver disease according to sleep duration. Chronobiol Int 2019;36:1671-80.

12 Bannai A, Tamakoshi A. The association between long working hours and health: a systematic review of epidemiological evidence. Scand $J$ Work Environ Health 2014;40:5-18.

13 Albertsen K, Borg V, Oldenburg B. A systematic review of the impact of work environment on smoking cessation, relapse and amount smoked. Prev Med 2006;43:291-305.

14 Okechukwu CA. Long working hours are linked to risky alcohol consumption. BMJ 2015;350:g7800.

15 Lee K, Suh C, Kim J-E, et al. The impact of long working hours on psychosocial stress response among white-collar workers. Ind Health 2017;55:46-53

16 Bhatia V, Tandon RK. Stress and the gastrointestinal tract. J Gastroenterol Hepatol 2005;20:332-9.

17 Azer SA, Akhondi H. Gastritis. StatPearls. Treasure Island, FL: StatPearls Publishing, 2020. https://www.ncbi.nlm.nih.gov/books/ NBK544250

18 Sipponen P, Maaroos H-I. Chronic gastritis. Scand J Gastroenterol 2015;50:657-67.

19 National Cancer Center (KR). National cancer screening program. Goyang: NCC, 1999. https://ncc.re.kr/main.ncc?uri=english/sub04 ControlPrograms 03
20 Park HK, Kim N, Lee SW, et al. The distribution of endoscopic gastritis in 25,536 heath check-up subjects in Korea. Korean $\mathrm{J}$ Helicobacter Up Gastroint Res 2012;12:237-43.

21 Rosta J, Gerber A. Excessive working hours and health complaints among hospital physicians: a study based on a national sample of hospital physicians in Germany. Ger Med Sci 2007;5:Doc09.

22 Spurgeon A, Harrington JM, Cooper CL. Health and safety problems associated with long working hours: a review of the current position. Occup Environ Med 1997;54:367-75.

23 European Association for the Study of the Liver (EASL), European Association for the Study of Diabetes (EASD), European Association for the Study of Obesity (EASO). EASL-EASD-EASO clinical practice guidelines for the management of non-alcoholic fatty liver disease. $J$ Hepatol 2016;64:1388-402.

24 Wen CP, David Cheng TY, Tsai SP, et al. Are Asians at greater mortality risks for being overweight than caucasians? Redefining obesity for Asians. Public Health Nutr 2009;12:497-506.

25 Jee SH, Jang Y, Oh DJ, et al. A coronary heart disease prediction model: the Korean heart study. BMJ Open 2014;4:e005025.

26 American Diabetes Association. Diagnosis and classification of diabetes mellitus. Diabetes Care 2014;37 Suppl 1:S81-90.

27 International Labour Organization. Hours of work (industry) convention, 1919 (NO. 1). International Labour Office. Geneva: ILO, 1919. https://www.ilo.org/dyn/normlex/en/f?p=NORMLEXPUB: 12100:0::NO::P12100 ILO CODE:C001

28 Dixon MF, Genta RM, Yardley JH, et al. Classification and grading of gastritis. The updated Sydney system. International workshop on the histopathology of gastritis, Houston 1994. Am J Surg Pathol 1996;20:1161-81.

29 Sung KC, Shim SC, Kim SH. Esophgogastroduodenoscopic findings in 9,137 healthy subjects examined for the secondary prevention. Korean J Gastrointest Endosc 1998;18:161-8 https://www.e-ce.org/ upload/pdf/29401288.pdf

30 Konturek PC, Brzozowski T, Konturek SJ. Stress and the gut: pathophysiology, clinical consequences, diagnostic approach and treatment options. J Physiol Pharmacol 2011;62:591-9.

31 Konturek PC, Brzozowski T, Burnat G, et al. Role of brain-gut axis in healing of gastric ulcers. J Physiol Pharmacol 2004;55:179-92.

32 Brzozowski T, Konturek PC, Pajdo R, et al. Importance of braingut axis in the gastroprotection induced by gastric and remote preconditioning. J Physiol Pharmacol 2004;55:165-77.

33 Holtmann G, Talley NJ. The stomach-brain axis. Best Pract Res Clin Gastroenterol 2014;28:967-79.

34 Guo G, Jia K-R, Shi Y, et al. Psychological stress enhances the colonization of the stomach by helicobacter pylori in the BALB/C mouse. Stress 2009;12:478-85.

$35 \mathrm{Kim}$ YH, Lee JH, Lee SS, et al. Long-term stress and helicobacter pylori infection independently induce gastric mucosal lesions in C57BL/6 mice. Scand J Gastroenterol 2002;37:1259-64.

36 Fatemeh N, Mohammad V, Hedayat S. Physical and psychological stress have similar effects on gastric acid and pepsin secretions in rat. J Stress Physiol Biochem 2011;7:1997-0838 https:// cyberleninka.ru/article/n/physical-and-psychological-stress-havesimilar-effects-on-gastric-acid-and-pepsin-secretions-in-rat/pd

37 Xie Y-F, Jiao Q, Guo S, et al. Role of parasympathetic overactivity in water immersion stress-induced gastric mucosal lesion in rat. $J$ App/ Physiol 2005;99:2416-22.

$38 \mathrm{Han} \mathrm{Y}, \mathrm{Li} \mathrm{Y}, \mathrm{Hu}$ Z, et al. Hydrogen sulfide-mediated resistance against water avoidance stress-induced gastritis by maintenance of gastric microbial homeostasis. Microbiologyopen 2020;9:e00951.

39 Chadolias D, Zissimopoulos A, Nena E, et al. Association of occupational exposures and work characteristics with the occurrence of gastrointestinal disorders. Hippokratia 2017;21:74-9.

40 Mahmoud SS, Gasmi FM, Solan YO. Prevalence and predictors of gastritis among patients attending health care facilities in Jazan, KSA. Int J Preven Pub Health Sci 2016;2:1-7.

41 Feyisa ZT, Woldeamanuel BT. Prevalence and associated risk factors of gastritis among patients visiting saint paul hospital millennium medical college, addis ababa, Ethiopia. PLoS One 2021;16:e0246619.

42 Liu ES, Wong BC, Cho $\mathrm{CH}$. Influence of gender difference and gastritis on gastric ulcer formation in rats. $J$ Gastroenterol Hepatol 2001;16:740-7.

43 Sogabe M, Okahisa T, Kimura T, et al. Influence of metabolic syndrome on upper gastrointestinal disease. Clin J Gastroenterol 2016;9:191-202.

44 Kotilea K, Bontems P, Touati E. Epidemiology, diagnosis and risk factors of helicobacter pylori infection. Adv Exp Med Biol 2019;1149:17-33.

45 Knutsson A, Bøggild H. Gastrointestinal disorders among shift workers. Scand J Work Environ Health 2010;36:85-95. 
46 Lee S, Chae $\mathrm{CH}$, Park C, et al. Relationship of shift work with endoscopic gastritis among workers of an electronics company. Scand J Work Environ Health 2020;46:161-7.

47 Correa P. Human gastric carcinogenesis: a multistep and multifactorial process--first american cancer society award lecture on cancer epidemiology and prevention. Cancer Res 1992;52:6735-40.

48 Correa P, Houghton J. Carcinogenesis of helicobacter pylori. Gastroenterology 2007;133:659-72.

49 Sipponen P, Riihelä M, Hyvärinen $\mathrm{H}$, et al. Chronic nonatropic ('superficial') gastritis increases the risk of gastric carcinoma. A casecontrol study. Scand J Gastroenterol 1994;29:336-40.
50 Owen DA. Gastritis and carditis. Mod Pathol 2003;16:325-41.

51 Ivey KJ. Acute haemorrhagic gastritis: modern concepts based on pathogenesis. Gut 1971;12:750-7.

52 Chamberlain CE. Acute hemorrhagic gastritis. Gastroenterol Clin North Am 1993;22:843-73.

53 Megha R, Farooq U, Lopez PP. Stress-Induced Gastritis. In: StatPearls [Internet]. Treasure Island (FL): StatPearls Publishing, 2021. 